\title{
A hybrid fuzzy-optimization method for modeling construction emissions
}

\author{
Mohamed Marzouk ${ }^{\mathbf{a}^{*}}$ and Eslam Mohammed Abdelakder ${ }^{\mathrm{b}}$
}

\begin{abstract}
${ }^{a}$ Professor of construction Engineering and Management, Structural Engineering Department, Faculty of Engineering, Cairo University, Egypt

${ }^{b}$ Ph.D. Candiate, Department of Building, Civil and Environmental Engineering, Concordia University, Montreal, QC, Canada

\begin{tabular}{l}
\hline C H R O N I C L E \\
\hline Article history: \\
Received July 25, 2019 \\
Received in revised format: \\
July 25,2019 \\
Accepted September 14, 2019 \\
Available online \\
September 14, 2019 \\
\hline Keywords: \\
Construction emissions \\
Building information modelling \\
Fuzzy \\
Non-dominated sorting genetic \\
algorithm II \\
TOPSIS
\end{tabular}

A B S T R A C T
Construction emissions have become a major concern that has risen extensively in the last few decades. This paper introduces a building information modeling (BIM)-based model to evaluate the environmental and economic consequences of different project alternatives. The model calculates direct, indirect emissions and primary energy for the overall project life cycle. A hybrid fuzzy multi-objective non-dominated sorting genetic algorithm II (NSGA-II) problem is designed to model the uncertainties associated with the quantification of the judging attributes, and consequently to find the most sustainable materials by minimizing the objective functions; project duration, project life cycle cost, project overall emissions and total project primary energy. Finally, TOPSIS is applied to select the most sustainable material for each construction component among the set of Pareto optimal solutions. A case study of an academic building in Saudi Arabia is presented in order to exemplify the practical features of the proposed model.
\end{abstract}

C 2020 by the authors; licensee Growing Science, Canada.

\section{Introduction}

Climate change is a mandatory phenomenon. Environmental pollution contributes significantly to the climate change. Greenhouse gases contribute significantly in the climate change, whereas these gases have a great influence on global temperature. According to the US National Oceanic and Atmospheric Administration (NOAA), the year 2015 was recorded as the hottest year since records started in 1880 . Moreover, the 16 year-period from 1998 to 2015 is considered as the warmest period ever (Olivier et al., 2016). The increase in the heat waves occurred due to the climate change, causes heat stroke, viral fever and dehydration (Pires et al., 2016). Many countries have perceived the importance of reducing greenhouse gases which led to some agreements and protocols, whereas the parties are required to minimize the greenhouse gas emissions below a specific baseline. Kyoto protocol is an international agreement that was introduced in December 1997 and it was linked to the United Nations Framework Convention on Climate Change to define the reduction targets in greenhouse gases. During the first commitment, the industrialized countries and European community have agreed to reduce the greenhouse gas emissions by 8\% below 1990 levels in the five-year period from 2008 to 2012. During the second commitment, the industrialized countries and European community have agreed to reduce the greenhouse gas emissions by $18 \%$ below 1990 levels in the eight-year period from 2013 to 2023 (Heidrich et al., 2016). The United States offered to reduce the greenhouse gas emissions by $17 \%$ below the 2005 levels by 2020 at the United Nations climate change conference in Copenhagen in 2009. Then,

* Corresponding author.

E-mail address: mm marzouk@yahoo.com (M. Marzouk)

(C) 2020 by the authors; licensee Growing Science, Canada. doi: $10.5267 /$ j.dsl.2019.9.002 
Under Paris agreement in 2015, the United States targeted to reduce greenhouse gases by $26 \%-28 \%$ below 2005 levels by 2025 (Parker et al., 2018). The construction industry is regarded as one of the most dynamic and ever changing sectors in world's economy. Construction of buildings has an inevitable impact on the environment. Building sector is possibly one of the most resource-intensive industries. Building sector is regarded as one of the main contributors of the environmental emissions. The amount of greenhouse gases has increased remarkably due to the rapid growth in urbanization and inefficiencies of the existing building stock. Building sector consumes over than $30 \%$ of the global energy consumption and nearly $30 \%$ of the global energy-related $\mathrm{CO}_{2}$ emissions (Dean et al., 2016). Based on the afore-mentioned statistics, dealing with environmental emissions became undoubtedly one of the greatest challenges in the recent century and minimizing environmental emissions produced from building sector is immense. The proposed research introduces a methodology that integrates Building Information Modeling with the calculation of time, life cycle cost, environmental impact and primary energy. The proposed model considers different project components as concrete foundations, beams, columns, slabs, walls, etc. Each project component is divided into a group of alternatives. Each alternative is assessed against the time needed to execute this alternative, alternative life cycle cost, emissions associated with this alternative and total primary energy associated with this alternative. Fuzzy set theory is incorporated to handle the uncertainties and vagueness associated with the quantification of the defining attributes of the different alternatives. Then, a multi-objective optimization problem is designed to select the scenarios that have the least duration, least life cycle cost, least emissions and least primary energy.

\section{Literature Review}

Several contributions have been made in the field of quantification and analyzing environmental emissions. Huang et al. (2017) introduced a calculation methodology for carbon footprint of urban buildings in Xiamen city in China. They concluded that the energy use phase and material production phase are responsible for $45 \%$ and $40 \%$ of the carbon footprint, respectively. They highlighted that the implementation of low-carbon strategies can result in the reduction of energy consumption of urban buildings by $2.98 \%$ in 2020 . Li et al. (2017) presented a hybrid simulation-optimization approach to minimize the $\mathrm{CO}_{2}$ emissions of on-site construction processes in cold regions. They concluded that optimizing labor allocation can result in a reduction in the on-site construction emissions by $21.7 \%$. Seo et al. (2016) analyzed the $\mathrm{CO}_{2}$ emissions produced from the material production phase, transportation phase, and construction phase. They highlighted that the manufacturing phase is the largest contributor of $\mathrm{CO}_{2}$ emissions with $93.4 \%$ followed by construction phase, and finally the transportation phase. Barati and Shen (2017) presented a methodology to minimize the operation emissions for on-road construction equipment. They stated that the emissions of the construction equipment increase significantly by increasing the payload of the equipment and the road slope. Abdallah et al. (2015) designed an optimization model that is capable of selecting the optimum building upgrade measures by minimizing the energy consumption while taking into consideration the budget constraints. The optimization model incorporates the analysis of the following systems, which are: interior and exterior lighting systems, HVAC (heating, ventilation and air conditioning) systems, water heaters, hand dryers, and renewable energy systems. Cho and Chae (2016) analyzed the emissions produced from low-carbon buildings and compared it with the emissions produced from the reference buildings. They highlighted that the low-carbon buildings can result in a $25 \%$ reduction in the carbon emissions. They illustrated that operation and maintenance phase represents the highest weight of $\mathrm{CO}_{2}$ emissions followed by manufacturing phase while construction phase represents the least contributor to $\mathrm{CO}_{2}$ emissions. Gonzalez and Navarro (2006) studied group of residential houses in Valladolid. They deduced that carbon emissions could be reduced by $30 \%$ in the case of usage of low environmental impact materials. Rai et al. (2011) investigated carbon footprint of light distribution warehouse. They concluded that carbon dioxide emissions could be reduced by $18 \%$ if timber cladding is used instead of steel cladding. Paya et al. (2009) introduced an optimization design model that minimizes carbon dioxide emissions and structural cost of reinforced concrete structures using simulated annealing approach. 


\section{Model Development}

The framework of the proposed research methodology is depicted in Fig. 1.

Step 1: Develop a building information model and define systems in Athena Impact Estimator
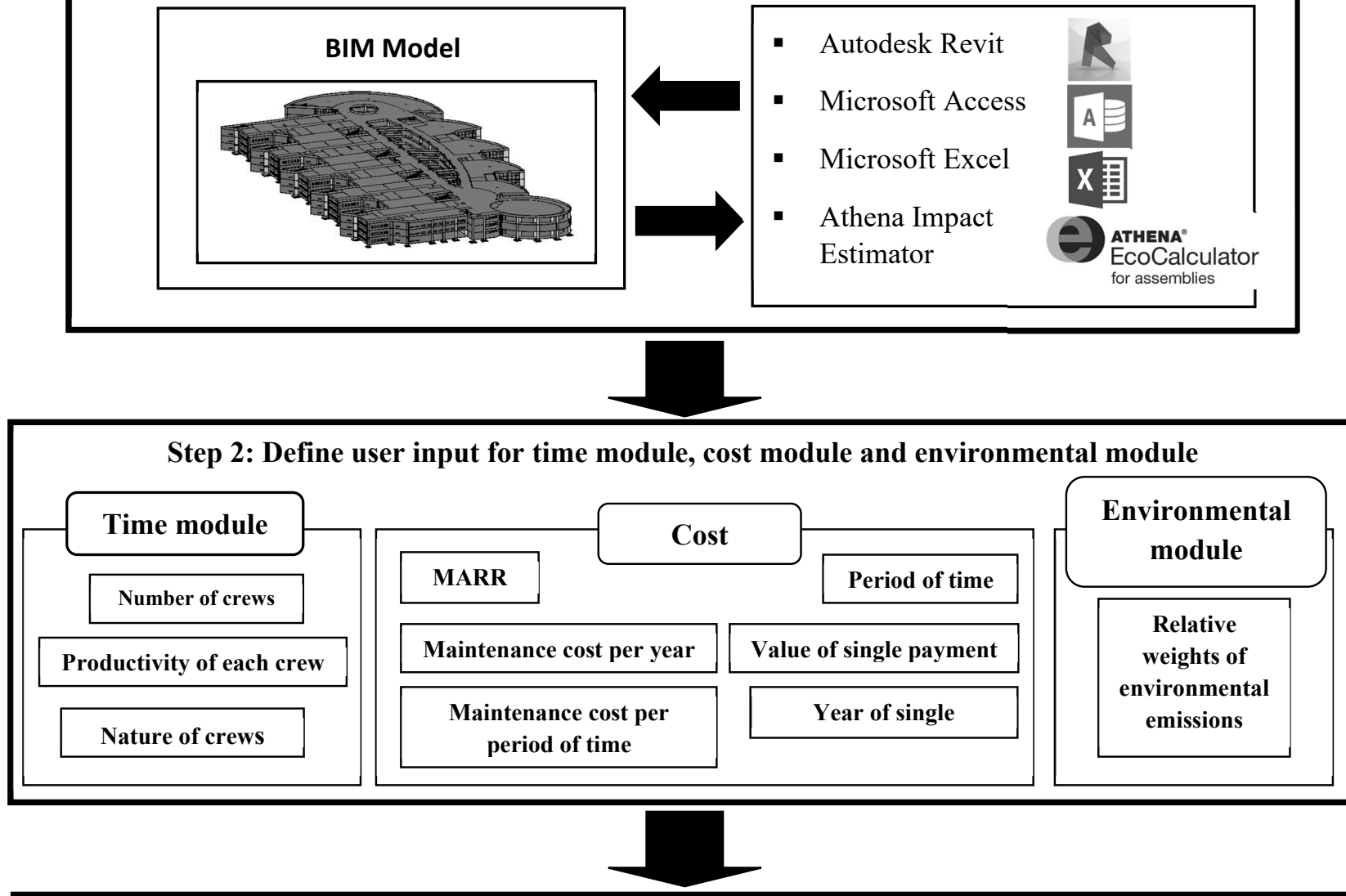

Step 3: Calculate de-fuzzified time, life cycle cost, environmental impact and primary energy for each alternative.

Manufacturin Transportation Constructio Maintenance Operation Recyclin Demolition

\section{Construction Projects Phases}

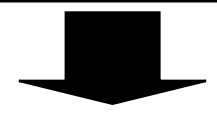

Step 4: Design a hybrid multi-objective optimization-decision making model

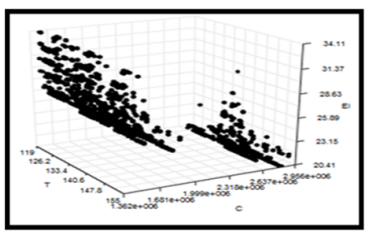

Fig. 1. Flowchart of the proposed research methodology 


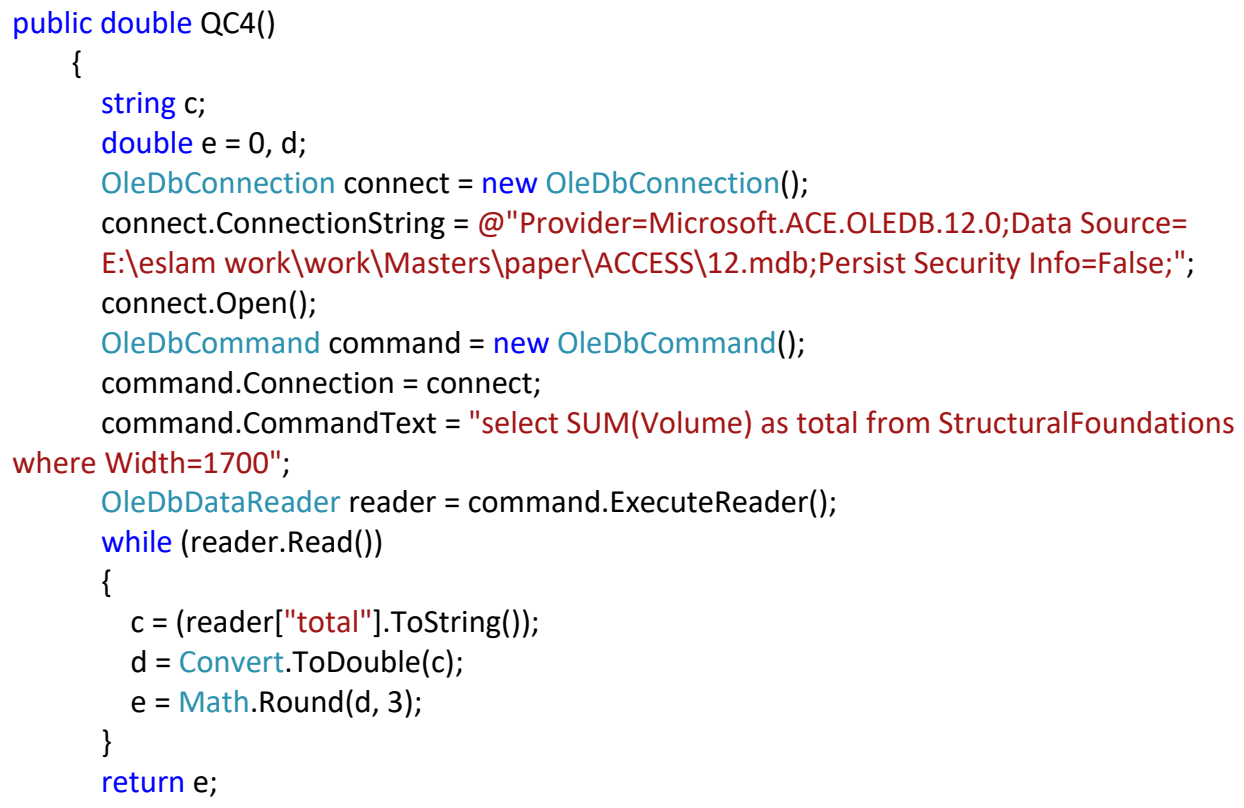

Fig. 2. Developed code to retrieve data from Microsoft Access

The developed model constitutes two sources of external inputs, which are the developed building information model and Athena Impact Estimator. The developed model is a building information modeling-based model where a 3D model is developed using Autodesk Revit (Autodesk Revit 2015). The 3D model constitutes a database. Revit DB link is a plug-in that enables all data concerning 3D model to be sent to Microsoft Access. A SQL statement is written inside the developed model in order to retrieve the data of the building information model from Microsoft Access to the proposed model (see Fig. 2). Athena Impact Estimator is the second source of external inputs. Properties of building systems including; the material type, the geometry of the building systems and size of reinforcement are defined inside Athena Impact Estimator software (Athena Impact Estimator 5.0.0105). The software calculates greenhouse gases footprint, sulfur dioxide, particular matter, eutrophication particles, ozone depletion particles and smog associated with each assembly for each phase of project life cycle. The interface of Athena Impact Estimator for the concrete foundations is depicted in Fig. 3.

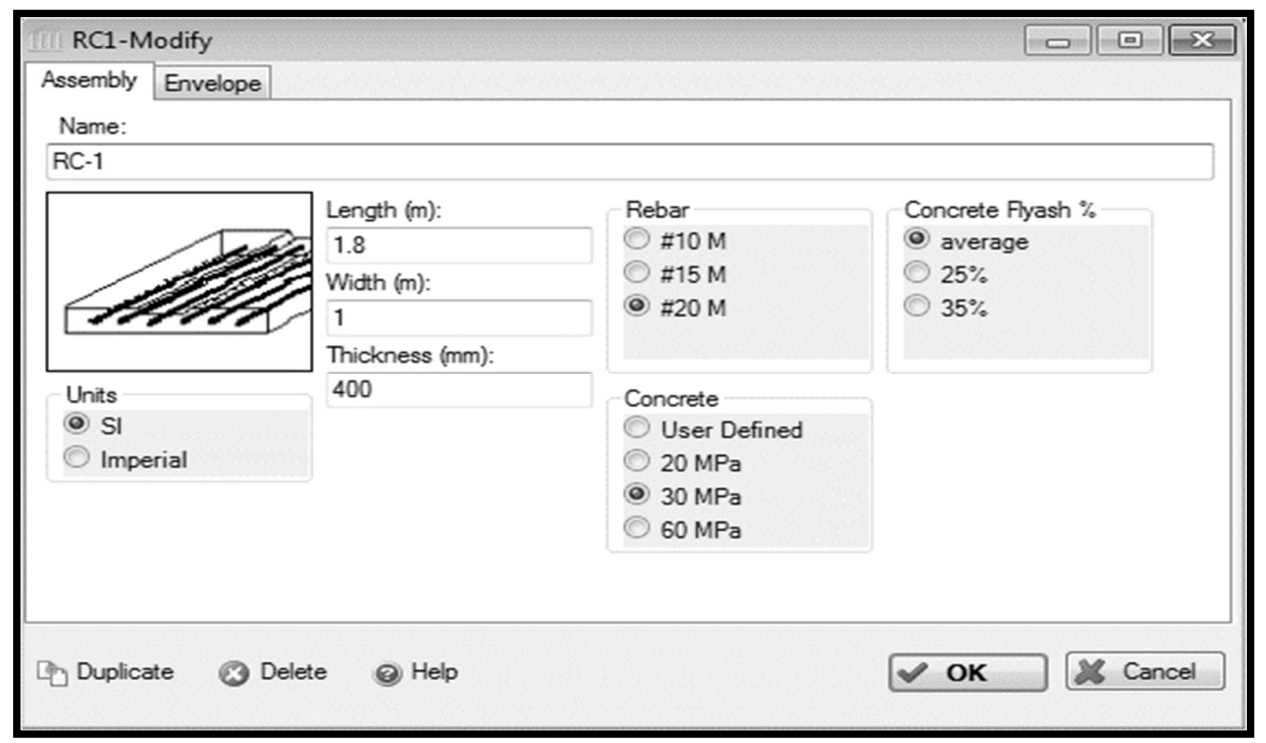

Fig. 3. Interface of Athena Impact Estimator 
The dimensions of the reinforced concrete, rebar size, concrete compressive strength and percentage of fly ash are defined for reinforced concrete foundations assembly. The output of the Athena Impact Estimator is in Microsoft Excel format. Another SQL statement is written in order to import data from Microsoft Excel to the proposed model (see Fig. 4).

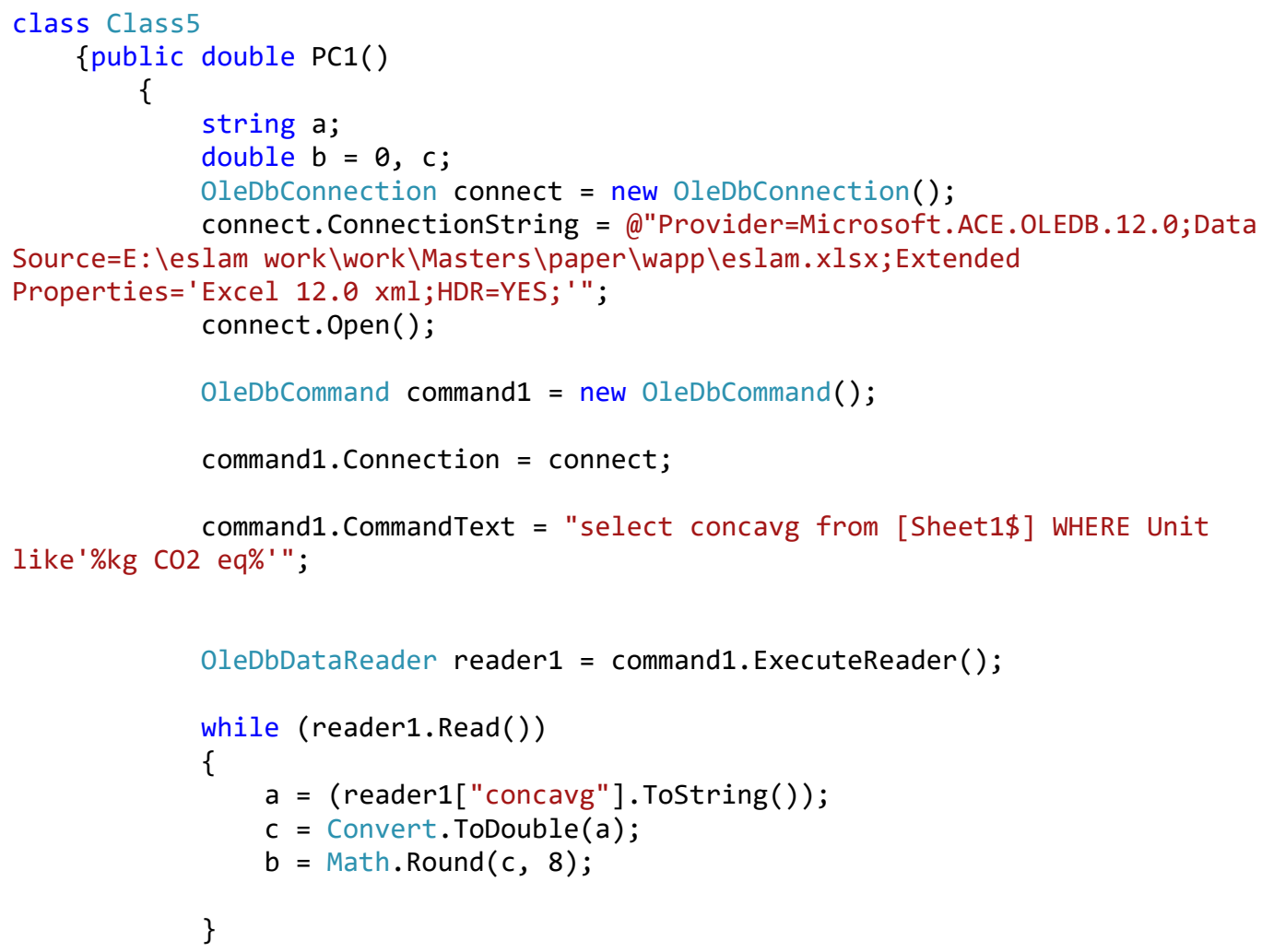

Fig. 4. Developed code to import data from Microsoft Excel

The automated software is divided into three modules, which are time module, cost module, and environmental module. The user is asked to determine certain inputs in each module. The user is asked to define the number of crews, the productivity of each crew and nature of crews (single-based crews or range-based crews) for each scenario for the time module. For the cost module, the user is asked to define some information in order to calculate total life cycle cost such as maintenance cost per year if exist, minimum attractive rate of return (MARR), maintenance cost per a specific period of time if exist, and to define this period of time such as 2 years, 5 years, 10 years, 25 years. The user is also asked to enter maintenance cost in a certain year if exist and to determine this year. For the environmental module, the user is asked to define the relative weights of the six different environmental emissions (W1, W2 W3, W4, W5, and W6) according to the emission he/she is more concerned with. Interface of the user input of the time module is shown in Fig. 5. "Check values" button is used to make sure that all the needed data are entered. The automated software calculates time, life cycle cost, environmental impact and primary energy of each scenario. The environmental impacts of different slab scenarios are shown in Fig. 6 . The fuzzy set theory to model the subjective uncertainty associated with the estimation of the time, lifecycle cost, environmental impact and primary energy consumption. A triangular membership function is constructed for each one of the four attributes for each alternative. Triangular fuzzy numbers are utilized because of their simplicity, usefulness in the data processing, and accurate representation of the fuzzy environment. For instance, the environmental impact membership function for the softwood lumber column and cast in situ column (see Fig. 7). 




Fig. 5. Interface of user input for time module

The values of the lower and upper bounds are obtained from the literature review. The fuzzy membership functions are de-fuzzified using the graded mean approach to convert the fuzzy number to a crisp number. The calculated attributes can be stored in the building information modeling (BIM) model as properties. A sample section of BIM model of this project is demonstrated in Figure 8 . The proposed model then exports the de-fuzzified attributes for different alternatives to Microsoft Excel in order to perform genetic algorithm optimization.

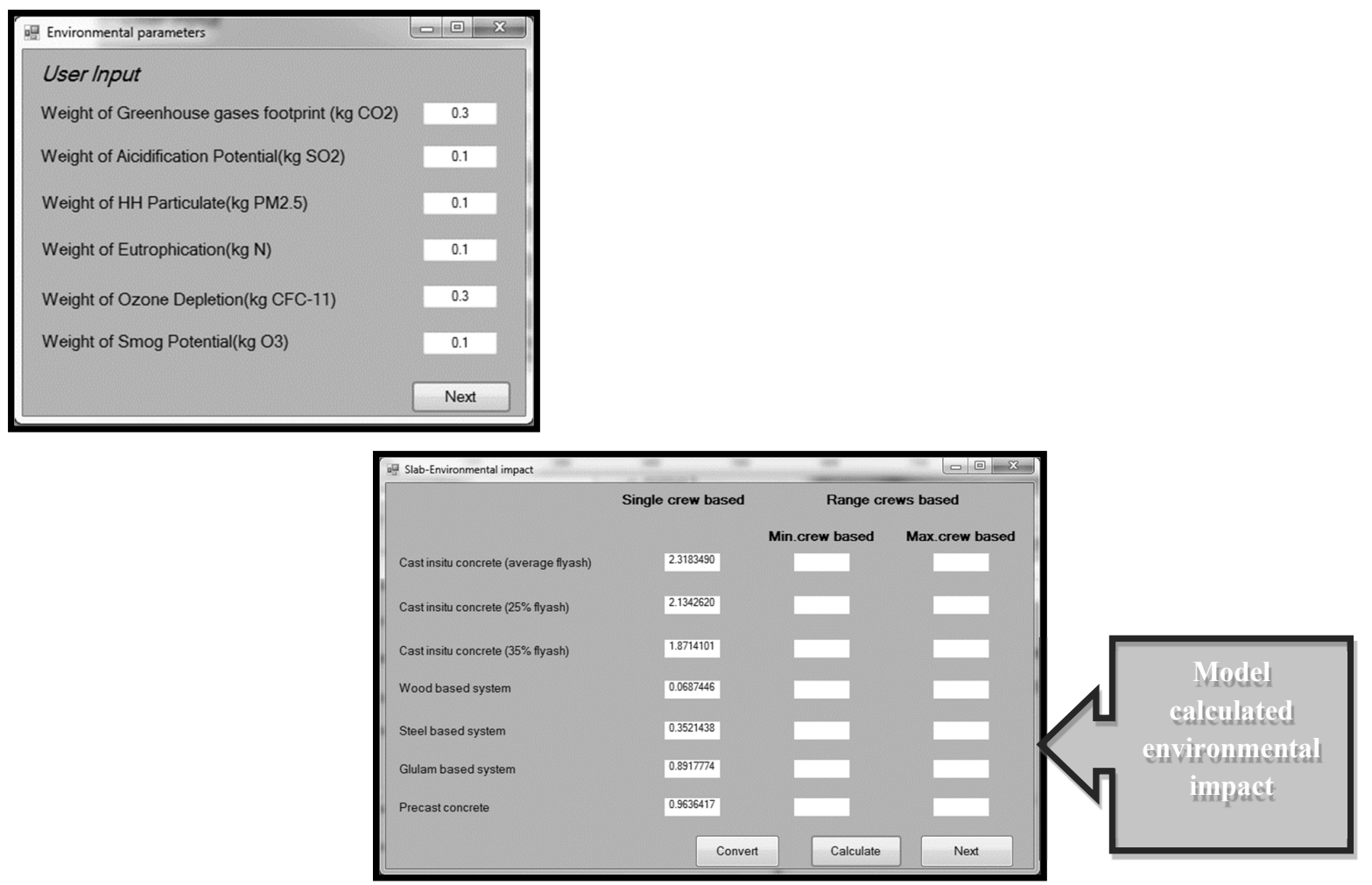

Fig. 6. Calculated environmental impact of the developed model 


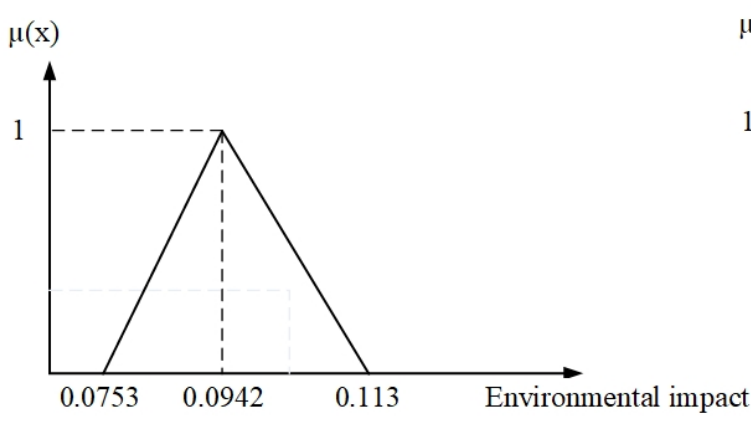

(a)

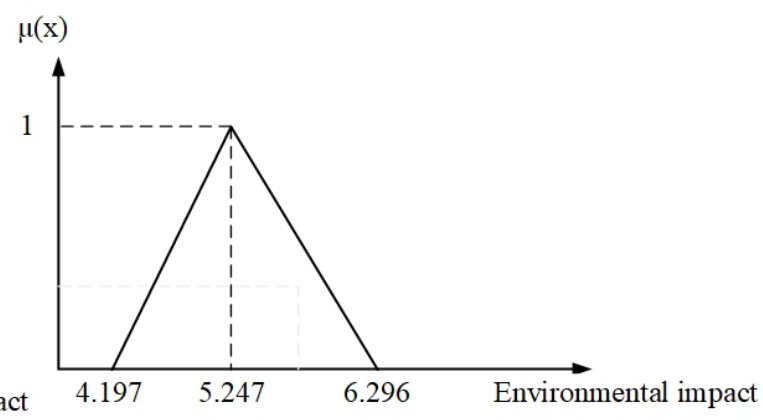

(b)

Fig. 7. Fuzzy membership functions of the environmental impact of (a) softwood lumber column and (b) cast in situ column

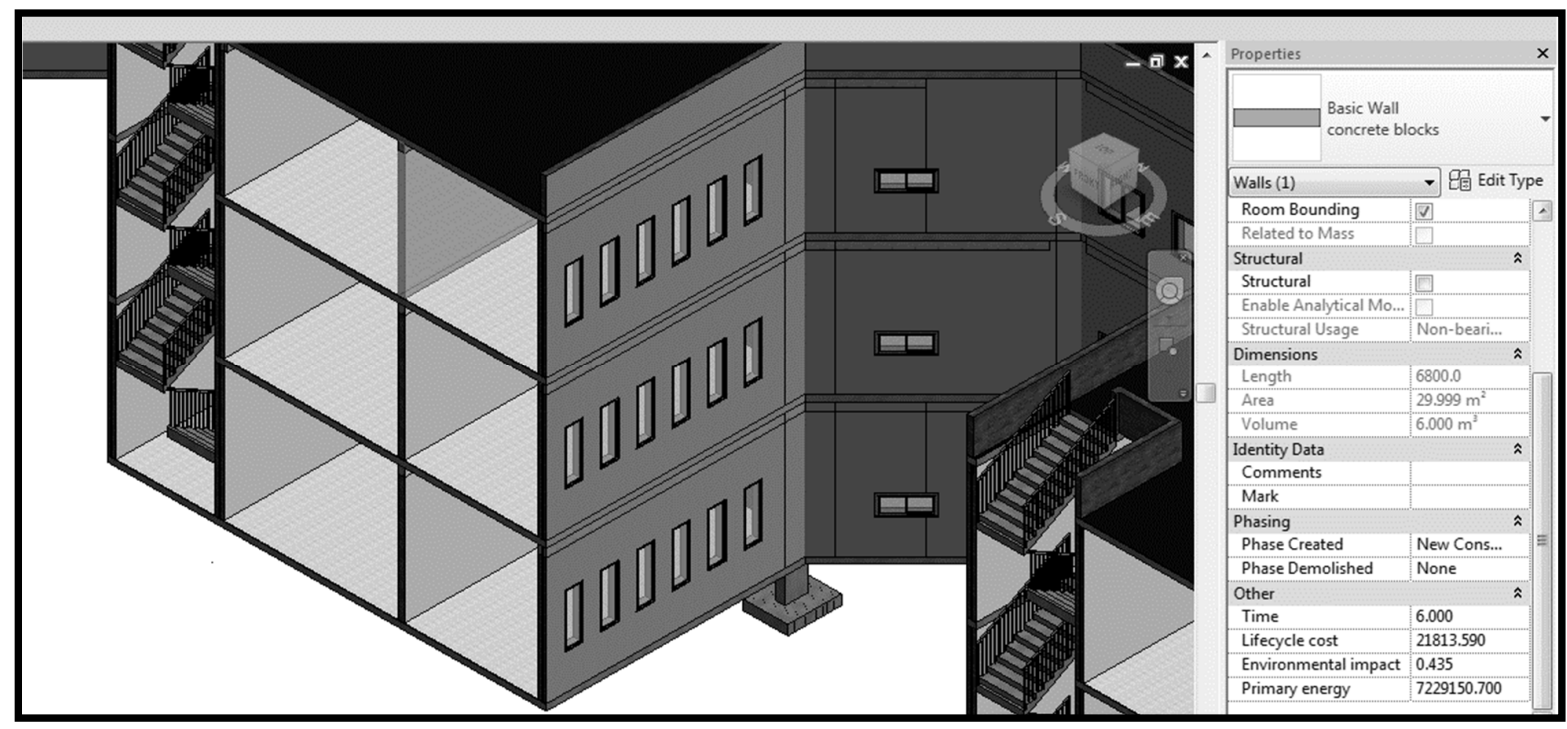

Fig. 8. Sample section of wall assembly

SolveXL plug-in is used for multi-objective optimization using non-dominated sorting genetic algorithm II (NSGA-II). Population size, crossover rate, mutation rate and the number of generations are defined. Different scenarios and objective functions are specified. Each cell in the software represents a certain assembly. There is a lower bound value and an upper bound value for each cell. The lower bound value represents the minimum number of scenarios while the upper bound value represents the maximum number of scenarios. The output of the model is the optimum set of alternatives to be performed for each construction assembly taking into account four objective functions, which are: construction time, life cycle cost, environmental impact, and consumed energy. The selection of a solution among the set of finite Pareto optimal solutions requires the implementation of multi-criteria decision making techniques. The weights of the attributes, which are the objective functions are obtained using Shannon entropy method, and finally Technique Order Preference by Similarity to Ideal Solution (TOPSIS) is applied to select the most feasible and comprehensive solution. 


\section{Calculation methodology of construction emissions}

\subsection{Direct and indirect emissions}

Direct emissions can be defined as emissions that are directly related to on-site construction processes. Direct emissions are calculated based on the amount of fuel consumed from equipment during construction processes. In other words, they are emissions generated from construction phase, transportation on -site phase, maintenance phase, deconstruction/demolition phase and recycling/reuse phase. Indirect emissions refer to emissions that are produced from off-site construction processes. They are emissions that are not directly related to the on-site construction process and generated at the upstream of the construction process. They include manufacturing emissions and transportation off-site emissions. Transportation off-site emissions are emissions that are generated from cradle to gate. The total emissions index is used to assess each alternative where overall emissions are divided into direct and indirect emissions. The direct emissions index, indirect emissions index, total emissions index and global emission index can be calculated using Eq. (1), Eq. (2), Eq. (3) and Eq. (4), respectively.

$$
\begin{aligned}
& \mathrm{EEd}=\mathrm{T} 1 \times\left(\text { EEghg } \text { EEghg }_{\text {sum }}\right)+\mathrm{T} 2 \times\left(\text { EEsu } / \text { EEsu }_{\text {Sum }}\right) \\
& +\mathrm{T} 3 \times\left(\text { EEpm } / \text { EEpm }_{\text {Sum }}\right)+\mathrm{T} 4 \times\left(\text { EEep } \text { EEep }_{\text {Sum }}\right) \\
& +\mathrm{T} 5 \times\left(\text { EEod } \text { EEod }_{\text {Sum }}\right)+\mathrm{T} 6 \times\left(\text { EEs }_{\text {EEs }} \text { Sum }_{\text {sum }}\right) \\
& \operatorname{EEd}^{\mathrm{i}}=\mathrm{T} 1 \times\left(\text { EEghg }^{\mathrm{i}} / \text { EEghg }_{\text {sum }}\right)+\mathrm{T} 2 \times\left(\mathrm{EEsu}^{\mathrm{i}} / \mathrm{EEsu}_{\text {Sum }}\right) \\
& +\mathrm{T} 3 \times\left(\mathrm{EEpm}^{\mathrm{i}} / \mathrm{EEpm}_{\text {Sum }}\right)+\mathrm{T} 4 \times\left(\mathrm{EEep}^{\mathrm{i}} / \mathrm{EEep}_{\text {Sum }}\right) \\
& +\mathrm{T} 5 \times\left(\text { EEod }^{\mathrm{i}} / \mathrm{EEod}_{\text {Sum }}\right)+\mathrm{T} 6 \times\left(\mathrm{EEs}^{\mathrm{i}} / \mathrm{EEs}_{\text {Sum }}\right) \\
& \mathrm{EE}^{\text {tot }}=\mathrm{EEd}+\mathrm{EEd}^{\mathrm{i}} \\
& \mathrm{EE}^{\text {global }}=\sum_{\mathrm{k}=1}^{\mathrm{n}} \mathrm{EE}^{\mathrm{tot}}(\mathrm{k})
\end{aligned}
$$

where; T1, T2, T3, T4, T5 and T6 represent modification index of greenhouse gases footprint, sulfur dioxide, particular matter, eutrophication particles, ozone depletion particles and smog, respectively. Each one of the modification indices is equal to severity index multiplied by a corresponding percentage. EEghg, EEsu, EEpm, EEep, EEod, and EEs denote the potentials produced from construction phase, transportation phase on-site, maintenance phase, deconstruction, and demolition phase and recycling/reuse phase for greenhouse gases footprint, sulfur dioxide, particular matter, eutrophication particles, ozone depletion particles and smog, respectively. EEghg sum $_{\text {, EEsu }}$ Sum,

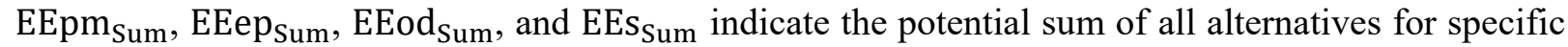
construction assembly including direct and indirect emissions of greenhouse gases footprint, sulfur dioxide, particular matter, eutrophication particles, ozone depletion particles and smog, respectively.

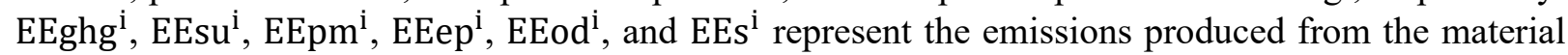
production, and transportation off- site phases for greenhouse gases footprint, sulfur dioxide, particular matter, eutrophication particles, ozone depletion particles and smog, respectively. k represents components (assemblies) of construction project. (EE ${ }^{\mathrm{tot}}$ ) represent the total emissions and it is calculated as the sum of direct and indirect emissions. $\mathrm{EE}^{\text {tot }}$ is unitless. EE ${ }^{\text {global }}$ indicates the global environmental impact of a construction project The greenhouse gases footprint produced from construction process $\left(\mathrm{EEghg}^{\mathrm{c}}\right)$ and transportation $\left(\mathrm{EEghg}^{\mathrm{t}}\right)$ process is calculated using the Eq. (5) and Eq. (6). 


$$
\begin{aligned}
& \text { EEghg }^{\mathrm{c}}=\sum_{\mathrm{j}=1}^{\mathrm{n}} \operatorname{Cons}_{A v g}(\mathrm{j}) * \text { Working hours }(\mathrm{j}) \times \operatorname{Act} \_ \text {work }(\mathrm{j}) \times \gamma_{\text {Diesel }} \times \mathrm{CEF} \times \mathrm{T}(\mathrm{j}) \\
& \text { EEghg }^{\mathrm{t}}=\sum_{\mathrm{i}=1}^{\mathrm{n}} \operatorname{Cons}_{\text {Avg }}(\mathrm{i}) \times \text { Working hours }(\mathrm{i}) \times \operatorname{Act} \_ \text {work }(\mathrm{i}) \times \gamma_{\text {Diesel }} \times \mathrm{CEF} \times \mathrm{T}_{\text {tra }}(\mathrm{i})
\end{aligned}
$$

where; $j$ represents the number of equipment utilized in the construction process of a specific construction element. $i$ denotes the number of equipment utilized in the transportation process on site. Working hours denotes the number of working hours of certain equipment ( 8 hours per day). Cons ${ }_{\text {Avg }}$ denotes the average consumption of a certain equipment (liters/hour). Act_work is percentage that the equipment will actually works. $\gamma_{\text {Diesel }}$ is density of diesel. CEF is carbon emission factor. The density of diesel is assumed $0.832 \mathrm{Kg} / 1$, whereas, the actual work of the equipment is $70 \%$ of its working hours, also the carbon emission factor for diesel is assumed $4 \mathrm{Kg} \mathrm{CO}_{2}-\mathrm{Eq} / \mathrm{Kg}$ (Flowe \& Sanjayan, 2007). $\mathrm{T}_{\text {tra }}$ represents the transportation time of a certain equipment.

Six weighted percentages (W1, W2 W3, W4, W5, and W6) are designated to each type of environmental air pollutants. The weighted percentages are the percentages of the six environmental emissions. The model allows the user to choose the environmental emissions that he is more concerned with. The sum of weighted percentages must be equal to one. The severity of each environmental emission must be taken into account as each environmental emission has a specific adverse effect on both human health and environment. Therefore, a qualitative index is used to assess the severity of each environmental pollutant. If the severity of air pollutant is very high, high, medium, low, very low then the corresponding severity index ranges from 8 to 10,6 to 8,4 to 6,2 to 4 and 1 to 2 , respectively.

\subsection{Operation emissions}

Emissions from the operation stage are produced from two main sources, which are electricity and natural gas. Operation emissions of equivalent carbon dioxide can be calculated using Eq. (7). The total quantity of equivalent carbon dioxide can be calculated by multiplying the quantity of each greenhouse gas by corresponding global warming g potential. The global warming potential for carbon dioxide, methane and nitrous oxide over a 100-year period are 1, 21 and 310, respectively (EPA, 2002). Operation emissions of sulfur dioxide can be calculated using equation 8. Operation emissions of particular matter can be calculated using equation 9. Operation emissions of smog can be calculated using Eq. (10). Emission factors of the different emissions obtained from the electricity consumption and the natural gas consumption are adopted from Zhang et al. (2013).

$$
\begin{aligned}
& \operatorname{Eghg}^{\text {op }}=\left(\left(\operatorname{EF}_{\text {ELEC }(j)_{\text {ghg }}} \times \text { Cons }_{\text {elec }}\right)+\left(\mathrm{EF}_{\mathrm{NGAS}_{(j)} \text { ghg }_{\text {g }}} \times \text { Cons }_{\text {ngas }}\right)\right) \times \operatorname{GWP}(\mathrm{j}) \\
& \mathrm{Epm}^{\mathrm{op}}=\left(\mathrm{EF}_{-} \mathrm{ELEC}_{\mathrm{pm}} \times \text { Cons_elec }\right)+\left(\mathrm{EF}_{-} \mathrm{NGAS}_{\mathrm{pm}} \times \text { Cons_ngas }\right) \\
& \text { Eap }^{\text {op }}=\left(\text { EF_ELEC }_{\text {ap }} \times \text { Cons_elec }\right)+\left(\text { EF_NGAS }_{\text {ap }} \times \text { Cons_ngas }\right) \\
& \mathrm{Es}^{\mathrm{op}}=\left(\mathrm{EF}_{-} E L E C_{\mathrm{s}} \times \text { Cons_elec }\right)+\left(\mathrm{EF}_{-} \mathrm{NGAS}_{\mathrm{s}} \times \text { Cons_ngas }\right)
\end{aligned}
$$

where; Cons_elec and Cons_ngas are the total consumed quantity of electricity and natural gas produced over the life span of the building, which is equal to average consumption of electricity consumption or natural gas consumption multiplied by area of the building and life span of the

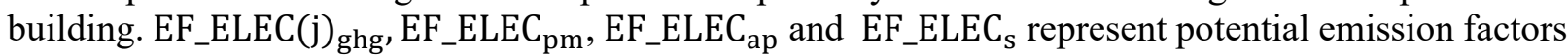
produced from electricity consumption of greenhouse gases footprint, particular matter, acidification potential and smog, respectively. $\mathrm{j}$ represents greenhouse gases and GWP represents the corresponding global warming potential. EF_NGAS(j) ghg $, \mathrm{EF}_{-} \mathrm{NGAS}_{\mathrm{pm}}, \mathrm{EF}_{-} \mathrm{NGAS}_{\mathrm{ap}}$ and $\mathrm{EF}_{-} \mathrm{NGAS}_{\mathrm{s}}$ represent potential emission factors produced from natural gas consumption of greenhouse gases footprint, 
particular matter, acidification potential and smog, respectively. The annual electricity consumption is assumed $200 \mathrm{kwh} / \mathrm{m}^{2}$. The annual natural gas consumption is assumed $28 \mathrm{~m}^{3} / \mathrm{m}^{2}$. A conversion factor is utilized in order to convert from $\mathrm{m}^{3} / \mathrm{m}^{2}$ of natural gas to $\mathrm{kwh} / \mathrm{m}^{2}$ where $1 \mathrm{~m}^{3} / \mathrm{m}^{2}$ of natural gas equals to $10.55 \mathrm{kwh} / \mathrm{m}^{2}$.

\subsection{Life cycle cost}

The life cycle cost is equal to the annual worth for different cost components. The life cycle cost is calculated in terms of LE/year. The life cycle is calculated based on the minimum attractive rate of return. The life cycle cost is calculated using Eq. (11).

$$
\text { Eap }^{\text {op }}=\left(\text { EF_ELEC }_{\text {ap }} \times \text { Cons_elec }\right)+(\text { EF_NGAS }
$$

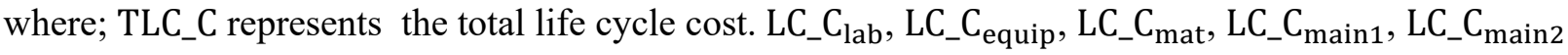
and $\mathrm{LC}_{-} \mathrm{C}_{\text {sing }}$ represent the equivalent annual worth for labor cost, material cost, equipment cost, maintenance cost per year, maintenance cost per period of time and single payment, respectively.

\subsection{Primary energy}

The primary energy that is utilized to assess the energy consumption of the different scenarios. It is calculated as the sum of the primary energy of different project stages. The proposed model will measure primary energy in terms of MJ (Mega joule). The overall primary energy is computed using Eq. (12).

$$
\mathrm{TPEC}=\mathrm{PEC}_{\text {manu }}+\mathrm{PEC}_{\text {tra-off }}+\mathrm{PEC}_{\text {cons }}+\mathrm{PEC}_{\text {oper }}+\mathrm{PEC}_{\mathrm{dec}}+\mathrm{PEC}_{\text {rec }}
$$

where; TPEC refers to total primary energy consumption. $\mathrm{PEC}_{\text {manu }}, \mathrm{PEC}_{\text {tra-off }}, \mathrm{PEC}_{\text {cons }}, \mathrm{PEC}_{\text {tra-on, }}$, $\mathrm{PEC}_{\text {oper }}, \mathrm{PEC}_{\mathrm{dec}}$ and $\mathrm{PEC}_{\mathrm{rec}}$ refer to primary energy consumed in manufacturing phase, transportation off-site phase, construction and transportation on-site phase, operation and maintenance phase, deconstruction and demolition phase and recycling and reuse phase, respectively. More details about the computation methods of the different parameters of the proposed method can be adopted from Marzouk et al. (2017a) and Marzouk et al. (2017b).

\section{Fuzzy set-theory}

Zadeh (1965) introduced the fuzzy set theory in 1965 to deal with the real-world problems that involve the linguistic descriptions. Fuzzy logic is used to construct the fuzzy inference system (FIS) in order to simulate human intelligence through approximate reasoning where an element can belong to a certain fuzzy set fully or partially. To perform the fuzzification process, it is necessary to define the universe of discourse, i.e., the input space or the set of all possible values that each input variable can take. Fuzzification is the process of converting the crisp values to fuzzy values through membership functions. The fuzzy sets are described by membership functions. The membership function is a mathematical function that defines the degree of membership of an element in a fuzzy set, i.e., the membership function defines how much an element belongs to a specific fuzzy set (Koduru et al., 2010). The degree of membership of each fuzzy is included in the interval $[0,1]$ where if the degree of membership of element $x$ is close to 1 , this means that element $x$ is close to belong to the fuzzy set. The proposed model considers the triangular membership function because in practice, it is better to deal with simple form membership functions such as triangular, trapezoidal, and sigmoidal functions (Tran et al., 2012). After establishing the overall membership function, the membership function is defuzzified. Defuzzification is the process of converting the fuzzy value into a crisp value. There are some defuzzification techniques such as maximum membership principle, centroid, bisector, maximum membership, and weighted average methods. Defuzzification is the process of converting the fuzzy numbers into crisp numbers. The proposed model utilizes graded mean approach for the defuzzification 
purposes. The triangular fuzzy membership function is de-fuzzified using Eq. (13) to convert it to a crisp number.

$$
D_{\mathrm{f}}^{-}=\frac{\mathrm{l}_{\mathrm{f}}+\left(4 \times \mathrm{m}_{\mathrm{f}}\right)+\mathrm{u}_{\mathrm{f}}}{6}
$$

where; $\mathrm{D}_{\mathrm{f}}^{-}$indicates the de-fuzzified crisp number. $\mathrm{l}_{\mathrm{f}}, \mathrm{m}_{\mathrm{f}}$ and $\mathrm{u}_{\mathrm{f}}$ represent the lower, middle and upper bounds of the triangular fuzzy membership, respectively.

\section{Non-dominated sorting genetic algorithm}

Genetic algorithm is one of the evolutionary algorithms. Genetic algorithm is very effective in solving very complex problems where hill-climbing derivative-based algorithms are trapped in local search solutions (Elbeltagi, et al., 2005). Moreover, genetic algorithm can handle multiple conflicting objectives directly and simultaneously. The steps of the genetic algorithm are depicted in Fig. 9.

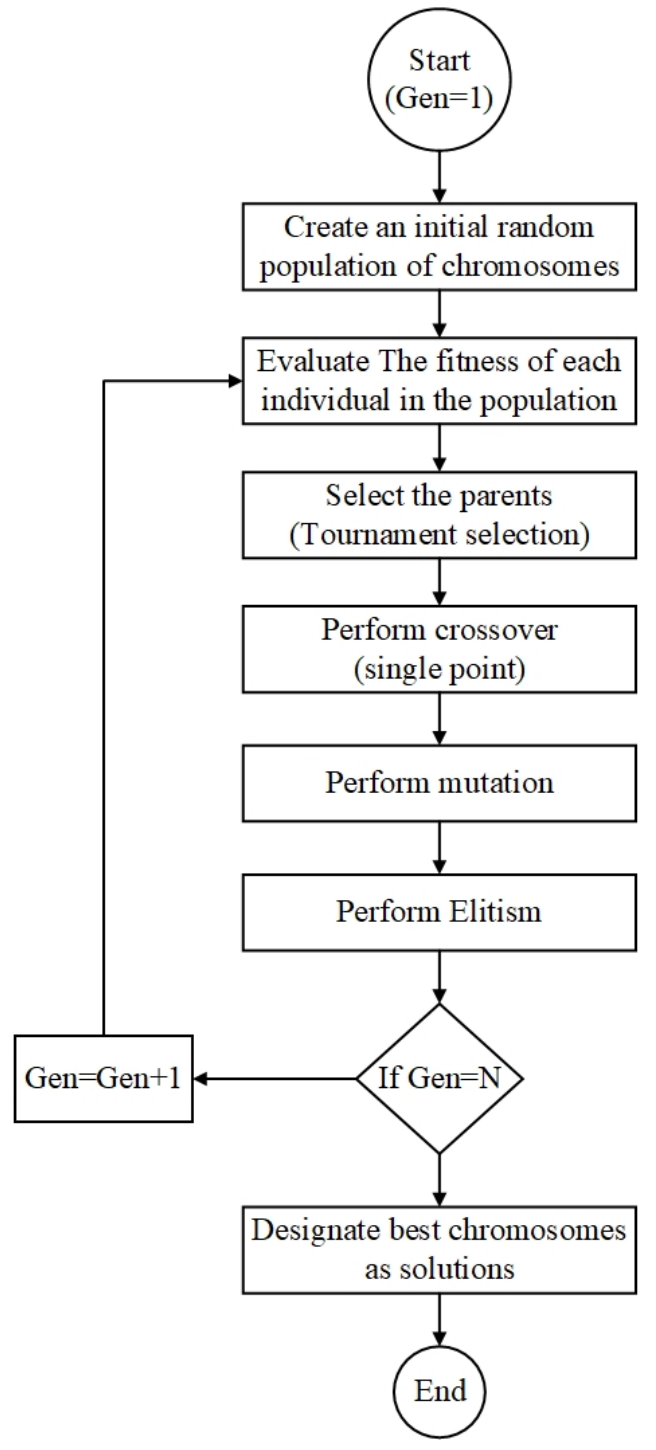

Fig. 9. Flowchart of the genetic algorithm

The first step is to form a random population of solutions where the solutions are represented in the form of string called "chromosomes". Each string is composed of characters called "binary numbers" or "digital numbers" representing decision variables. Chromosomes may be also called "individuals". 
In genetic algorithms, a solution to a problem is an "individual" and the group of solutions in each stage is a "population". Each stage a new population of individuals is created is called "generation". Chromosomes consist of genes that carry set of values for the optimization variables. The second step is to calculate the fitness function for each chromosome in the population. Fitness function is a measure of performance of decision variables. Fitness function is used to assess different chromosomes. There may be more than one fitness function in case of multi-objective optimization. The fitness of each chromosome is determined by evaluating it against objective function. The third step is selection of chromosomes. The selection process determines which chromosomes will mate to form new chromosomes. There are different types of chromosomes selection strategies which are: roulette wheel selection, rank selection, steady-state selection, elitism, Boltzmann selection and tournament selection. The tournament selection is performed as follows. For each parent in tournament selection strategy, random selection of individuals is chosen. The number of individuals is called the "tournament size". The random selected individuals compete against each other in the tournament selection strategy. The chromosome that has the highest fitness wins and it will be included in the next generation. The fourth step is to perform crossover. Crossover is a very important process to generate an offspring between two chromosomes or individuals. There are different types of crossover as single point crossover, twopoint crossover and uniform crossover. The most common type of crossover is single point crossover where you choose a point at which you swap the remaining genes from one parent to another. The point where crossover is performed is chosen randomly (Razali \& Geraghty, 2011). The fifth step is to perform mutation. The mutation gene is chosen randomly. The process of mutation occurs by looping through all genes of individuals and if a gene is selected for mutation, the gene will be changed by a small value or it will be replaced by a new value. Mutation is done in order to ensure that individuals are not exactly the same and to ensure genetic diversity within the population. Mutation is also performed to avoid stagnation around local minima (Heidari \& Movaghar, 2011). The mutation rate is usually less than 0.1. Elitism is an important strategy as there is a probability of losing best chromosomes during crossover and mutation. The chromosomes are arranged in a decreasing order and the best chromosomes are copied to the next generation. Finally, a population is generated in each generation and the above processes continue for certain number of iterations. The chromosomes in the final iteration are the solutions. As mentioned before, the proposed optimization model utilizes NSGAII to find the optimum solutions. The model applies multi-objective optimization with four objective functions. The first objective function is to minimize total project duration and it is calculated using Eq. (14). This function takes into consideration different relationships between construction activities. The model uses critical path method (CPM) to calculate total project duration. The second objective function is to minimize total project cost and it is calculated using Eq. (15). The third objective function is to minimize total project emissions and it is calculated using Eq. (16). The fourth objective function is to minimize total project primary energy and it is calculated using Eq. (17).

$$
\begin{aligned}
& \mathrm{F} 1=\min \mathrm{TPT}=\min \mathrm{CP}\left(\text { Time }_{\mathrm{m}}\right) \\
& \mathrm{F} 2=\min \mathrm{TPC}=\min \sum_{\substack{\mathrm{m}=1 \\
\mathrm{n}}}^{\mathrm{n}} \text { Cost }_{\mathrm{m}} \\
& \mathrm{F} 3=\min \mathrm{TPEI}=\min \sum_{\mathrm{m}=1}^{\mathrm{n}} \mathrm{Etot}_{\mathrm{m}} \\
& \mathrm{F} 4=\min \mathrm{TPEN}=\min \sum_{\mathrm{m}=1}^{\mathrm{n}} \text { Ene }_{\mathrm{m}}
\end{aligned}
$$

where; $\mathrm{m}$ represents activities of the construction project. CP is an operator, which represents the critical path of the project. TPT, TPC, TPEI and TPEN represent total project time, cost, environmental impact and primary energy, respectively. Time, Cost, Etot and Ene represent duration, cost, environmental impact and primary energy of a construction activity. 


\section{Multi-criteria decision making}

Multi-criteria decision making (MCDM) techniques are a group of methods that allow aggregation and consideration different attributes in order to rank alternatives and choose the best alternative. There are three steps that most multi-criteria decision making techniques pursue which are (Mulliner et al., 2013): 1) define relevant alternatives and attributes, 2) link numerical measures to the relative importance of different attributes and to the impact of alternatives on these attributes and 3) apply numerical measures to sort and rank different alternatives. Evaluation criteria in MCDM can be divided into two main clusters which are (Stanujkić et al., 2013): 1) benefit criteria where the higher measure of performance is the better one, 2) cost criteria where the lower measure of performance is the better one. Evaluation criteria can also be divided into objective and subjective criteria. Subjective criteria are characterized by their qualitative nature and measures of performance are often expressed in linguistic terms, whereas, objective criteria are characterized by their quantitative nature, therefore performance rating of this kind of attributes is measured in a precise way. In most of the decision making problems, evaluation criteria have certain relative weights. These weights have a great impact on the ranking of alternatives. The proposed model employs multi-criteria decision-making techniques to select the most feasible solution based on the results obtained from the multi-objective optimization module. Shannon entropy is employed to compute the weights of the attributes and then TOPSIS is utilized to rank the Pareto optimal solutions and to obtain the best solutions. More details about the applications of the multi-criteria decision making can be found in Marzouk et al. (2017c) and Abdelkader et al. (2019).

\subsection{Shannon entropy}

The concept of Shannon entropy is introduced in order to calculate the weights of attributes. Shannon introduced the concept of information entropy in 1948. Entropy can be defined as average amount of information. The criteria weights in the entropy method are calculated according to the degree of index dispersion. Shannon entropy calculation methodology is divided into four steps (Akyene, 2012): The first step is to calculate the Weight $\left(\mathrm{P}_{\mathrm{ij}}\right)$ which is calculated using Eq. (18).

$$
P_{i j}=\frac{x_{i j}}{\sum_{i=1}^{m} x_{i j}} \quad(1 \leq \mathrm{i} \leq \mathrm{m}, 1 \leq \mathrm{j} \leq \mathrm{n})
$$

where; $\mathrm{P}_{\mathrm{ij}}$ represents the weight of the $\mathrm{i}$-th alternative with respect to $j$-th attribute. $x_{i j}$ represents measure of performance of the $\mathrm{i}$-th alternative with respect to $j$-th attribute. Entropy value of $\mathrm{j}$-th attribute is calculated using Eq. (19). The second step is to calculate the Entropy value and it is calculated using Eq. (19).

$$
\mathrm{e}_{\mathrm{j}}=-\mathrm{k} * \sum_{\mathrm{j}=1}^{\mathrm{n}} \mathrm{P}_{\mathrm{ij}} \times \ln \mathrm{P}_{\mathrm{ij}}(1 \leq \mathrm{i} \leq \mathrm{m}, 1 \leq \mathrm{j} \leq \mathrm{n})
$$

where;

$$
\mathrm{k}=\frac{1}{\ln (\mathrm{m})}
$$

where; $e_{j}$ refers to the Entropy value of $j$-th attribute. The third step is to calculate variation coefficient for different attributes and it is calculated using Eq. (20).

$$
\mathrm{d}_{\mathrm{j}}=1-\mathrm{e}_{\mathrm{j}}
$$

where; $d_{j}$ represents variation coefficient of $j$-th attribute. The fourth step is to weight for each attribute and it is calculated using Eq. (21). 


$$
w_{j}=\frac{d_{j}}{\sum_{j=1}^{n} d_{j}}
$$

where; $w_{j}$ represents weight of each attribute.

\subsection{Topsis}

TOPSIS utilizes the Euclidean distances to compare the alternatives using the positive and negative ideal solutions as a reference. TOPSIS decision making technique is divided into five main steps (Dragia et al., 2013): The decision matrix is normalized where the purpose of this step is to convert performance attributes into non dimensional ones.

$$
r_{i j}=\frac{x_{i j}}{\sum_{i=1}^{m} x^{2}{ }_{i j}}
$$

The weighted normalized matrix is obtained using Eq. (23).

$$
v_{i j}=r_{i j} \times w_{j}
$$

The ideal and negative ideal solutions are determined. $\mathrm{A}^{*}$ indicates the most preferable alternative or ideal solution. On the contrary, $\mathrm{A}^{-}$indicates the least preferable alternative or negative ideal solution. For benefit criteria, decision maker wants to obtain the maximum value among all alternatives. On the other hand, the decision maker wants to obtain minimum value among all alternatives for cost criteria.

$$
\begin{aligned}
& \mathrm{A} *=\left\{\left(\max _{\mathrm{ijj}} \mid \mathrm{j} \in \mathrm{J}\right),\left(\min _{\mathrm{ij}_{\mathrm{j}}} \mid \mathrm{j} \in \mathrm{J}^{\prime}\right), \mathrm{i}=1,2,3 \ldots \mathrm{M}\right\}=\left\{\mathrm{v} *_{1}, \mathrm{v} *_{2} \ldots \ldots \ldots \mathrm{v} *_{\mathrm{N}}\right\} \\
& A-=\left\{\left(\min v_{i j} \mid j \in J\right),\left(\max v_{i j} \mid j \in J^{\prime}\right), i=1,2,3 \ldots . \mathrm{M}\right\}=\left\{v-{ }_{1}, v-{ }_{2} \ldots \ldots \ldots \mathrm{v}-{ }_{\mathrm{N}}\right\}
\end{aligned}
$$

where;

$$
\begin{gathered}
J=\{, j=1,2,3, \ldots \ldots \ldots \mathrm{N} \mid \mathrm{j} \text { associated with benefit criteria }\} \\
J^{\prime}=\{, j=1,2,3, \ldots \ldots \ldots \mathrm{N} \mid \mathrm{j} \text { associated with cost criteria }\}
\end{gathered}
$$

The fourth step is to calculate the separation distance of each alternative to the ideal and negative ideal solutions. $s_{i}^{*}$ represents the separation distance of each alternative in the Euclidean way from the ideal solution. On the contrary, $s_{i}^{-}$represents the separation distance of each alternative in the Euclidean way from the negative ideal solution.

$$
\begin{aligned}
& s_{i}^{*}=\sqrt{\sum_{i=1}^{n}\left(v_{i j}-v_{j}^{*}\right)} \\
& s_{i}^{-}=\sqrt{\sum_{j=1}^{n}\left(v_{i j}-v_{j}^{-}\right)}
\end{aligned}
$$

The fifth step is to calculate the relative closeness of an alternative $A_{i}$ to the ideal solution $A^{*}$. The relative closeness is calculated using Eq. (28). The larger $c_{i}^{*}$ the closer to the ideal solution. Alternatives are ranked in descending order.

$$
c_{i}^{*}=\frac{s_{i}^{-}}{s_{i}^{*}+s_{i}^{-}}
$$




\section{Model implementation}

The practical case considered for application of the proposed model is an actual project in Saudi Arabia (educational building). The case study considers an actual project in Saudi Arabia as depicted in the BIM model (see Fig. 10). More details about the alternatives of the case study can be found in Marzouk et al. (2017a). It consists of three typical floors with isolated footings. Area of one floor is approximately $9100 \mathrm{~m}^{2}$. The weighted percentages $(W 1, W 2, W 3, W 4, W 5$ and $W 6)$ of greenhouse gases footprint, sulfur dioxide, particular matter, eutrophication particles, ozone depletion particles and smog are $0.3,0.1,0.1,0.1,0.3$ and 0.1 , respectively. The MARR is assumed 6\%. Life-span of the building is assumed 50 years. Maintenance cost per year is assumed $1 \%$ of the initial cost. Maintenance cost per specific period is assumed $1 \%$ of the initial cost every 25 years. Single payments are assumed for each assembly. The proposed model considers 102 scenarios. The multiobjective optimization selects the optimum solutions based on the previously-mentioned objective functions. The walls are divided into external and internal walls.



Fig. 10. Building information model for the case study

The practical case study constitutes $2.75 \times 10^{12}$ combinations. The present optimization problem is a discrete optimization problem that constitutes a large search, which requires the implementation of meta-heuristics. The population size is assumed 1500. The crossover rate is assumed 0.9. The mutation rate is assumed 0.05. The number of generations is assumed 750. Tournament selection strategy is implemented for parent selection. A sample of the optimal solutions is shown in Table 1. The better solutions are the solutions that have the least execution time, least life cycle cost, least environmental impact and least energy consumed.

Table 1

Sample of optimal solutions

\begin{tabular}{|c|c|c|c|c|c|}
\hline Alternative no. & Associated scenarios & $\begin{array}{c}\text { Total Duration } \\
\text { (days) }\end{array}$ & $\begin{array}{l}\text { Lifecycle Cost } \\
\text { (LE/year) }\end{array}$ & $\begin{array}{c}\text { Environmental } \\
\text { Impact }\end{array}$ & $\begin{array}{c}\text { Primary } \\
\text { Energy }(\mathbf{M J})\end{array}$ \\
\hline 98 & $6,6,6,4,4,7,1,2,15,12,3,2,2,7,1$ & 121 & $1,435,604$ & 27.85 & $88,861,419$ \\
\hline 240 & $6,6,6,4,4,7,1,2,15,12,3,2,6,7,1$ & 124 & $1,470,030$ & 26.95 & $85,848,218$ \\
\hline 312 & $6,6,6,4,4,7,3,2,15,4,3,2,2,7,1$ & 125 & $1,641,896$ & 26.04 & $68,884,647$ \\
\hline 825 & $6,6,6,4,4,6,3,2,15,4,3,2,2,7,1$ & 140 & $1,606,944$ & 25.75 & $58,529,871$ \\
\hline 1081 & $6,6,6,4,4,4,1,2,15,4,3,2,2,7,1$ & 143 & $2,560,041$ & 22.42 & $50,105,692$ \\
\hline 1293 & $6,6,6,2,4,4,3,3,4,4,3,2,6,7,1$ & 147 & $2,820,051$ & 20.55 & $45,589,778$ \\
\hline
\end{tabular}

Results of optimal solutions are depicted in Fig. 11 where T, C, EI and EN stand for time, life cycle cost, environmental impact, and primary energy, respectively. Fig. 10 is divided into four different graphs. Each graph represents the generated optimum solutions in a $3 \mathrm{D}$ environment. The solutions 
represented in black nodes (500 solutions) have less project duration than solutions in red nodes in Fig. 11.a. The solutions of black nodes (500 solutions) have smaller life cycle cost than solutions in red nodes in Fig. 11.b. The solutions depicted in black nodes (500 solutions) have less environmental impact than solutions in red nodes in Fig. 11.c. The solutions of black nodes (500 solutions) in Fig. 11.d have less primary energy than solutions in red nodes. Time, life e cycle cost, environmental impact and primary energy are the attributes of multi-criteria decision making techniques. Shannon entropy method is used as weight determination methodology to calculate weights of decision making techniques. The weights of attributes are illustrated in Table 2. Calculations show that life cycle cost constitutes the largest weight by $48.12 \%$ while total duration represents the smallest weight by $3.76 \%$. The best three ranking solutions obtained from TOPSIS in addition to the values of their attributes alongside with their numerical measures (relative closeness) are depicted in Table 3. A solution is chosen in order to be analyzed in terms of emissions produced in each life cycle of the project (see Table 4). The contribution of project life cycle phases in greenhouse gases footprint, sulfur dioxide, particular matter, eutrophication particles, ozone depletion particles and smog and primary energy are depicted in Fig. 12. The results show that the operation phase represents the highest weight in greenhouse gases footprint with $85.93 \%$. Deconstruction and demolition phase has the least contribution in producing greenhouse gases footprint with $0.58 \%$. Operation phase has the highest contribution of sulfur dioxide with $84.95 \%$ while recycling and reuse phase has the least contribution with $0.32 \%$. Manufacturing and transportation off-site phases have the highest contribution in producing particular matter with $50.53 \%$. On the other hand, deconstruction and demolition phase has the least contribution with $0.48 \%$. Maintenance phase represents the highest weight of eutrophication potential with $53.31 \%$ while operation phase and recycling and reuse phases have the least contribution with $0 \%$ and $1.59 \%$, respectively.

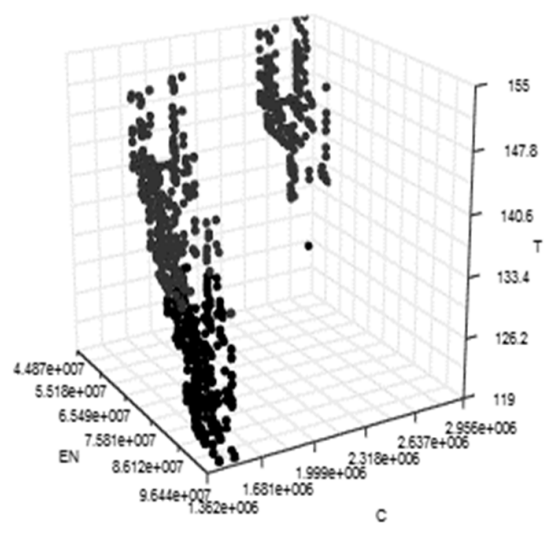

(a)

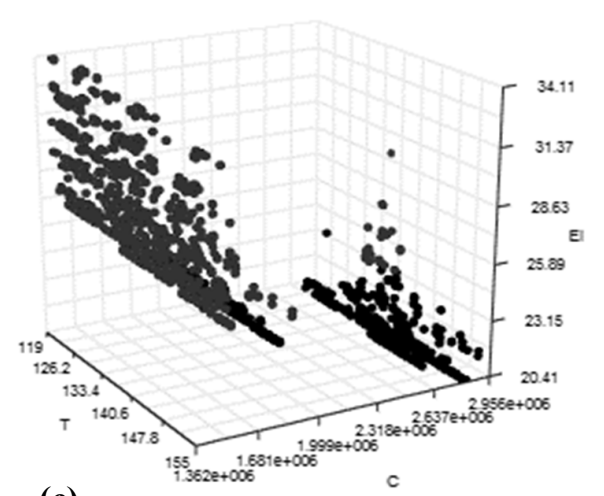

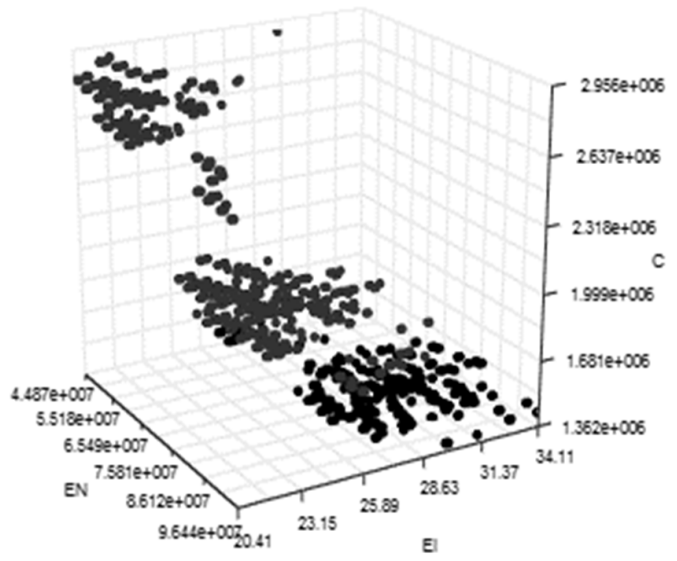

(b)

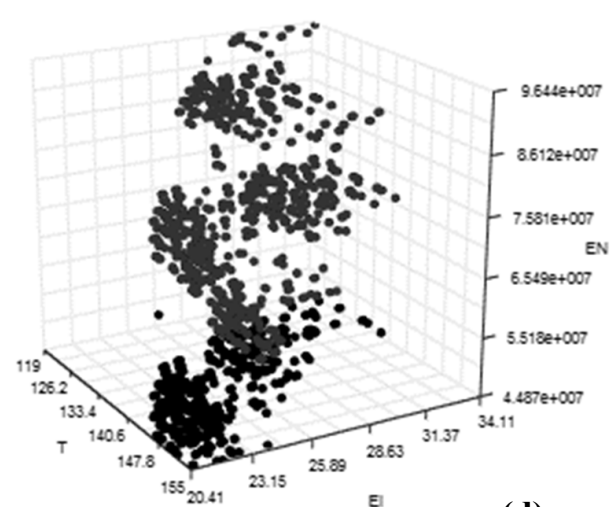

(d)

Fig. 11. Generated solutions from optimization module 
Manufacturing and transportation off-site phases represent the highest weight of ozone depletion potential with $93.58 \%$ while recycling and reuse phase and operation phase constitute $0 \%$. Manufacturing and transportation off-site phases have the highest contribution in producing smog with $39.08 \%$ while recycling and reuse phase has the least contribution with $0.92 \%$. Operation phase constitutes the largest weight of primary energy with $87.09 \%$ while recycling and reuse phase represents $0.15 \%$. Operation phase is maximum in primary energy consumption. Manufacturing and transportation off-site phase is maximum in ozone depletion potential. The maintenance phase is maximum in eutrophication potential. Deconstruction and demolition phase is maximum in smog. Recycling and reuse phase is maximum in eutrophication potential. Construction and transportation onsite phase is maximum in smog. This paper investigates six different types of environmental emissions as mentioned before. The contribution of each environmental pollutant in terms of weight of the chosen combination is depicted in Fig. 13. This graph shows that greenhouse gases have the largest contribution with $97.52 \%$ while ozone depletion has the smallest contribution with nearly equal zero value. Acidification potential, human health particulate, eutrophication potential and smog represent $0.539 \%, 0.073 \%, 0.006 \%$ and $1.86 \%$, respectively.

Table 2

Entropy value, variation coefficient and weight of attributes

\begin{tabular}{ccccc} 
Terms & $\begin{array}{c}\text { Total Duration } \\
\text { (days) }\end{array}$ & $\begin{array}{c}\text { Lifecycle Cost } \\
\text { (LE/year) }\end{array}$ & Environmental Impact & $\begin{array}{c}\text { Primary Energy } \\
\text { (MJ) }\end{array}$ \\
\hline$e_{j}$ & 0.999362 & 0.991826 & 0.998744 & 0.993083 \\
$d_{j}$ & 0.000638 & 0.008174 & 0.001256 & 0.006917 \\
$w_{j}$ & $3.76 \%$ & $48.12 \%$ & $7.4 \%$ & $40.72 \%$ \\
\hline
\end{tabular}

Table 3

Description of the best three solutions obtained from TOPSIS

\begin{tabular}{|c|c|c|c|c|c|c|}
\hline $\begin{array}{c}\text { Alternative } \\
\text { Ranking }\end{array}$ & Optimal Solutions & $\begin{array}{c}\text { Total Duration } \\
\text { (days) }\end{array}$ & $\begin{array}{c}\text { Life cycle Cost } \\
\text { (LE/year) }\end{array}$ & $\begin{array}{c}\text { Environmental } \\
\text { Impact }\end{array}$ & $\begin{array}{c}\text { Primary } \\
\text { Energy (MJ) }\end{array}$ & $\boldsymbol{c} *_{i}$ \\
\hline 1 & $6,6,6,2,4,6,3,3,15,4,3,2,14,7,1$ & 143 & $1,615,859$ & 25.78 & $54,134,262$ & 0.8293 \\
\hline 2 & $6,6,6,4,4,6,1,2,15,4,3,2,14,7,1$ & 143 & $1,587,842$ & 25.876 & $55,834,542$ & 0.8234 \\
\hline 3 & $6,6,6,4,4,6,3,2,15,4,3,2,14,7,1$ & 143 & $1,586,999$ & 25.911 & $55,880,935$ & 0.8232 \\
\hline
\end{tabular}

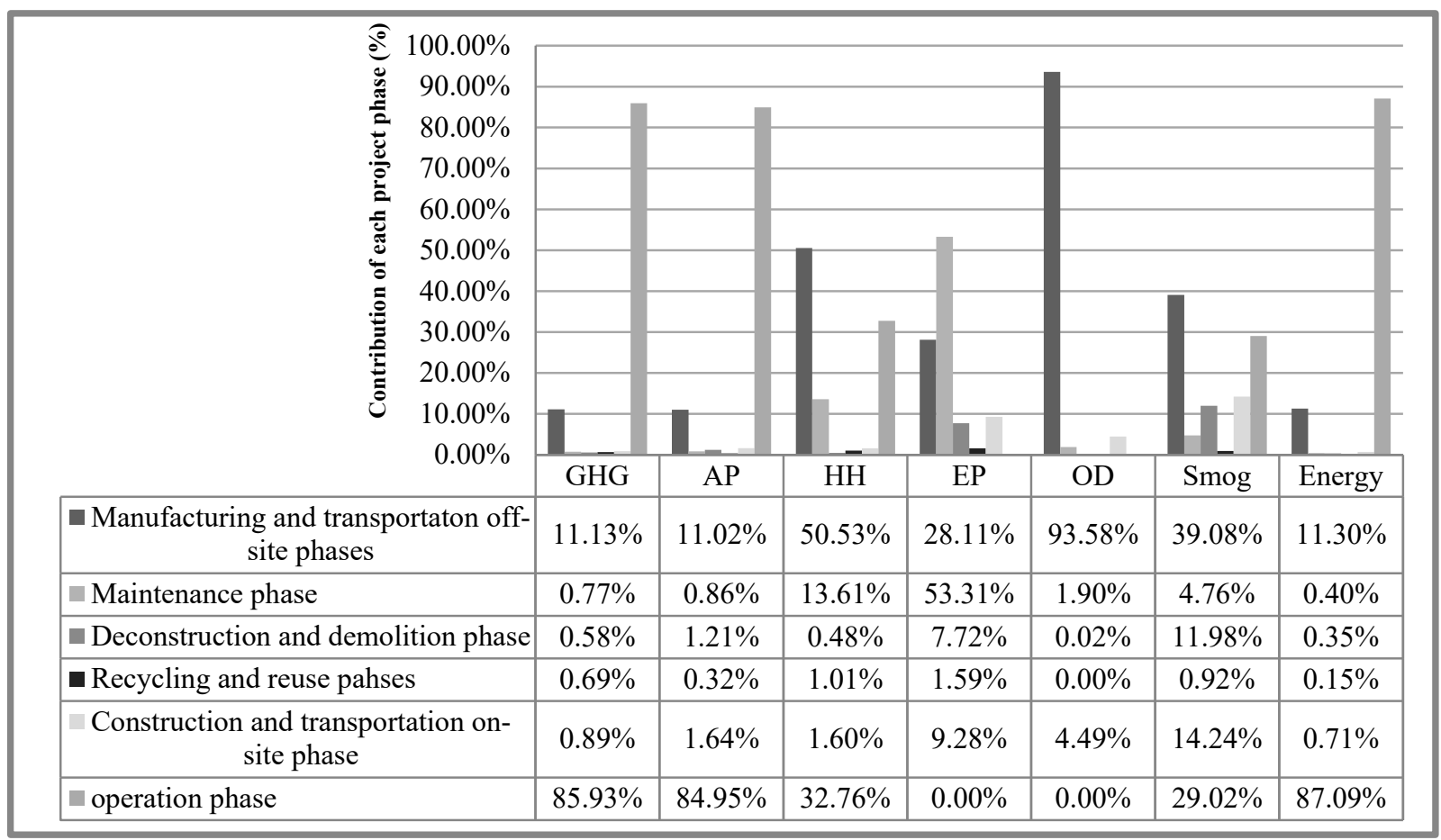

Fig. 12. Contribution of project life cycle phases in producing different environmental emissions and primary energy 
Table 4

Attributes associated with the chosen solution

\begin{tabular}{ccccc}
\hline Combination & $\begin{array}{c}\text { Total Duration } \\
\text { (days) }\end{array}$ & $\begin{array}{c}\text { Life cycle Cost } \\
\text { (EGP/year) }\end{array}$ & $\begin{array}{c}\text { Environmental } \\
\text { Impact }\end{array}$ & $\begin{array}{c}\text { Primary } \\
\text { Energy (MJ) }\end{array}$ \\
\hline $1,1,1,1,4,1,6,5,14,1,2,3,1,6,8$ & 246 & $5,067,528$ & 85.7 & $166,159,651.3$ \\
\hline
\end{tabular}

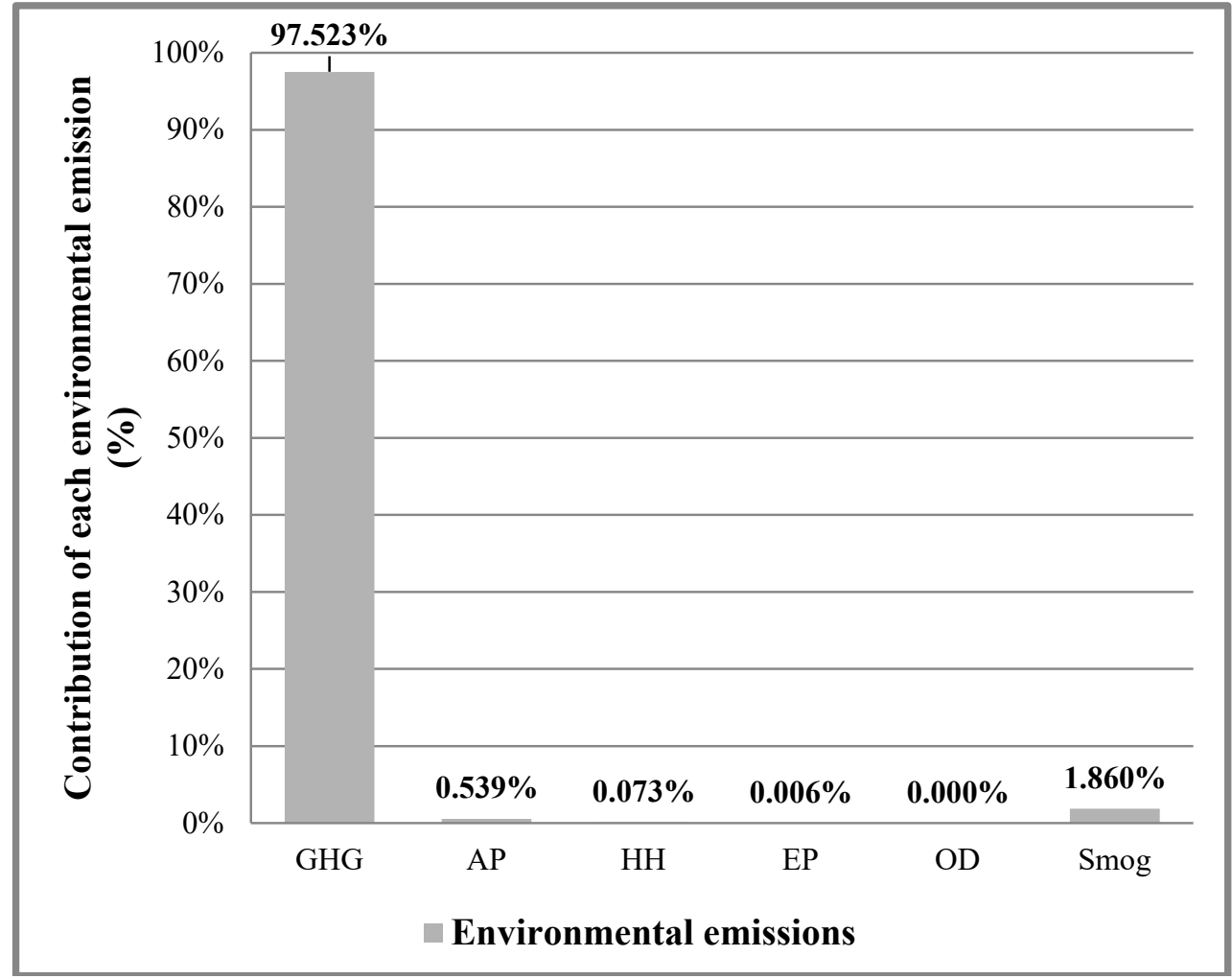

Fig. 13. Contribution of environmental emissions by weight

\section{Conclusion}

Building-related environmental issues have increased significantly in the last few years. Environmentally harmful activities differ from one industry to another but construction industry has established itself as one of the major sources of environmental emissions. This paper presented a decision tool that enables decision makers to select the most sustainable construction alternatives based on a hybrid model that combined both fuzzy-set theory, multi-objective optimization and multi-criteria decision making. This paper investigated six different types of environmental emissions, which are greenhouse gases footprint, sulfur dioxide, particular matter, eutrophication particles, ozone depletion particles and smog in terms of quantity and severity. It demonstrated that construction emissions are produced during all project life cycle phases as manufacturing phase, transportation phase, construction phase, maintenance phase, operation phase, recycling/reuse phase and deconstruction/demolition phase. Each project component is divided into group of alternatives. These alternatives represent scenarios of different assemblies of the construction project systems including: walls, beams, slabs, cladding, painting, etc. Each alternative is assessed against the time needed to execute this alternative, alternative life cycle cost, and emissions associated with this alternative. The fuzzy-set theory is used to handle the uncertainties of the different attributes. A multi-objective optimization problem is designed to find the optimal solutions. Then, TOPSIS technique is applied to select the most feasible solution among the finite set of optimal solutions. An automated tool is developed using C\#.net language to facilitate the implementation of the proposed method. 
A further emissions analysis study is conducted, which illustrated that all the different phases of the project contribute in producing emissions with certain weights such as operation phase, which constitutes the higher contribution in greenhouse gases footprint. On the other hand, manufacturing and transportation off-site phases constitute the large weight of particular matter, therefore all emissions and phases should be taken into account. It introduced a methodology to calculate project duration, project life cycle cost, project overall emissions and total project primary energy associated with these alternatives. Finally, the present study analyzed a case study and presented a group of alternatives for different project assemblies to demonstrate the capabilities of the proposed method. Thus, society and people who are concerned with environmental issues should turn their attention towards using sustainable materials as they reduce environmental pollution by a considerable amount.

\section{References}

Abdallah, M., El-Rayes, K., \& Clevenger, C. (2015). Minimizing energy consumption and carbon emissions of aging buildings. Procedia Engineering, 118, 886-893.

Akyene, T. (2012). Cell phone evaluation base on entropy and TOPSIS. Interdisciplinary Journal of Research in Business, 1(12), 9-15.

Athena Impact Estimator 5.0.0105. (2016). Available at: http://calculatelca.com/software/impactestimator/download-impact-estimator/ (Accessed Feb 1, 2016).

Autodesk Revit (2015). Available at: http://www.autodesk.com/education/free-software/revit (Accessed Dec 29, 2015).

Barati, K., \& Shen, X. (2017). Optimal driving pattern of on-road construction equipment for emissions reduction. Procedia engineering, 180, 1221-1228.

Cho, S. H., \& Chae, C. U. (2016). A study on life cycle CO2 emissions of low-carbon building in South Korea. Sustainability, 8(6), 579.

Dean, B., Dulac, J., Petrichenko, K., \& Graham, P. (2016). Towards zero-emission efficient and resilient buildings Global Status Report 2016, Global Alliance for Buildings and Construction. Available at: http://www.planbatimentdurable.fr/IMG/pdf/gabc_report.pdf (Accessed June 24, 2018).

Elbeltagi, E., Hegazy, T., \& Grierson, D. (2005). Comparison among five evolutionary-based optimization algorithms. Advanced Engineering Informatics, 19(1), 43-53.

Flower, D. J., \& Sanjayan, J. G. (2007). Green house gas emissions due to concrete manufacture. The international Journal of Life Cycle Assessment, 12(5), 282.

González, M. J., \& Navarro, J. G. (2006). Assessment of the decrease of CO2 emissions in the construction field through the selection of materials: Practical case study of three houses of low environmental impact. Building and Environment, 41(7), 902-909.

Heidari, E., \& Movaghar, A. (2011). An efficient method based on genetic algorithms to solve sensor network optimization problem. arXiv preprint arXiv:1104.0355.

Heidrich, O., Reckien, D., Olazabal, M., Foley, A., Salvia, M., de Gregorio Hurtado, S., ... \& Hamann, J. P. (2016). National climate policies across Europe and their impacts on cities strategies. Journal of Environmental Management, 168, 36-45. Huang, W., Li, F., Cui, S. H., Huang, L., \& Lin, J. Y. (2017). Carbon Footprint and Carbon Emission Reduction of Urban Buildings: A Case in Xiamen City, China. Procedia engineering, 198, 1007-1017.

Koduru, H. K., Xiao, F., Amirkhanian, S. N., \& Juang, C. H. (2010). Using fuzzy logic and expert system approaches in evaluating flexible pavement distress: Case study. Journal of Transportation Engineering, 136(2), 149-157.

Li, H. X., Zhang, L., Mah, D., \& Yu, H. (2017). An integrated simulation and optimization approach for reducing $\mathrm{CO} 2$ emissions from on-site construction process in cold regions. Energy and Buildings, 138, 666-675.

Marzouk, M., Abdelkader, E. M., \& Al-Gahtani, K. (2017). Building information modeling-based model for calculating direct and indirect emissions in construction projects. Journal of cleaner production, 152, 351-363. 
Marzouk, M., Abdelkader, E. M., El-zayat, M., \& Aboushady, A. (2017). Assessing environmental impact indicators in road construction projects in developing countries. Sustainability, 9(5), 843.

Marzouk, M., \& Abdelkader, E. M. (2017). Minimizing Construction Emissions Using Building Information Modeling and Decision-Making Techniques. International Journal of 3-D Information Modeling (IJ3DIM), 6(2), 14-35.

Abdelkader, E. M., Marzouk, M., \& Zayed, T. (2019). An optimization-based methodology for the definition of amplitude thresholds of the ground penetrating radar. Soft Computing, 1-24..

Mulliner, E., Smallbone, K., \& Maliene, V. (2013). An assessment of sustainable housing affordability using a multiple criteria decision making method. Omega, 41(2), 270-279.

Razali, N. M., \& Geraghty, J. (2011, July). Genetic algorithm performance with different selection strategies in solving TSP. In Proceedings of the world congress on engineering (Vol. 2, No. 1, pp. 1-6). Hong Kong: International Association of Engineers..

Olivier, J. G. J., Janssens-Maenhout, G., Muntean, M., \& Peters, J. A. H. W. (2015). Trends in global CO2 emissions: 2015 Report. PBL Netherlands Environmental Assessment Agency, The Hague; European Commission, Joint Research Centre (JRC). Institute for Environment and Sustainability (IES).

Parker, C. F., \& Karlsson, C. (2018). The UN climate change negotiations and the role of the United States: assessing American leadership from Copenhagen to Paris. Environmental Politics, 27(3), 519-540.

Paya-Zaforteza, I., Yepes, V., Hospitaler, A., \& Gonzalez-Vidosa, F. (2009). CO2-optimization of reinforced concrete frames by simulated annealing. Engineering Structures, 31(7), 1501-1508.

Bettencourt Pires, M. A., Vilemar Magalhaes, J., \& Gupta, P. D. (2016). Heat waves in nonconventional areas, climate change and disease load: A review. Journal of Cell and Tissue Research, 16(2), 5705-5711.

Rai, D., Sodagar, B., Fieldson, R., \& Hu, X. (2011). Assessment of CO2 emissions reduction in a distribution warehouse. Energy, 36(4), 2271-2277.

Seo, M. S., Kim, T., Hong, G., \& Kim, H. (2016). On-site measurements of CO2 emissions during the construction phase of a building complex. Energies, 9(8), 599.

Stanujkić, D., Đorđević, B., \& Đorđević, M. (2013). Comparative analysis of some prominent MCDM methods: A case of ranking Serbian banks. Serbian journal of management, 8(2), 213-241.

Tran, D., Mashford, J., May, R., \& Marlow, D. (2011). Development of a fuzzy risk ranking model for prioritizing manhole inspection. Journal of Computing in Civil Engineering, 26(4), 550-557.

Zadeh, L. A. (1965). Fuzzy sets. Information and control, 8(3), 338-353.

Zhang, X., Shen, L., \& Zhang, L. (2013). Life cycle assessment of the air emissions during building construction process: A case study in Hong Kong. Renewable and Sustainable Energy Reviews, 17 , 160-169.

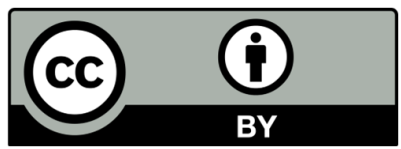

(C) 2020 by the authors; licensee Growing Science, Canada. This is an open access article distributed under the terms and conditions of the Creative Commons Attribution (CC-BY) license (http://creativecommons.org/licenses/by/4.0/). 